\title{
Prospections en haute vallée du Toulourenc
}

\section{Pierre André}

\section{OpenEdition \\ Journals}

Édition électronique

URL : http://journals.openedition.org/adlfi/7129

ISSN : 2114-0502

Éditeur

Ministère de la culture

Référence électronique

Pierre André, "Prospections en haute vallée du Toulourenc », ADLFI. Archéologie de la France -

Informations [En ligne], Rhône-Alpes, mis en ligne le 01 mars 2007, consulté le 03 mai 2019. URL

http://journals.openedition.org/adlfi/7129

Ce document a été généré automatiquement le 3 mai 2019.

(c) Ministère de la Culture et de la Communication, CNRS 


\title{
Prospections en haute vallée du Toulourenc
}

\author{
Pierre André
}

Date de l'opération : 2007 (PI)

1 La haute vallée du Toulourenc, de sa source jusqu'au bassin de Montbrun-les-BainsReilhanette, articule d'une part un axe de circulation nord-est atypique à la géomorphologie des Baronnies méridionales et offre d'autre part la singularité de se situer dans une zone de transition entre deux imposantes réserves de matières siliceuses, celles du plateau de Sault et celles des combes de Veaux.

\section{Commune d'Aulan}

2 Les différentes collections privées, dont celle du dernier comte de Suarez, m'ont incité à rendre compte de l'état actuel à partir des informations du terrain. La commune d'Aulan est constituée d'une cuvette argilomarneuse où s'ouvre à la fois la source du Toulourenc mais aussi les cols qui communiquent au nord vers la rivière Ouvèze et à l'est vers la rivière Méouge, affluent de la Durance. Des quatre communes prospectées, Aulan est celle qui présente les sols les plus fortement érodés, du fait de leur couverture marneuse mais aussi par un défrichement intensif (arrachage des résineux) afin de créer des zones de pâturage.

3 Le lieu-dit La Palud est le seul à formaliser réellement un site. Une terre noirâtre, cendreuse, s'étale sur environ $50 \mathrm{~m}^{2}$ et offre à l'oeil de nombreux éclats siliceux de factures anthropiques; certains ayant subit des chocs thermiques, d'autres plus rares, débités après chauffe. Un tiers des artéfacts lithiques présentent des surfaces corticales et deux fragments de roche allochtone (quartzite) complètent la série. Les objets remarquables se composent d'un grattoir, de deux pointes de flèches, (une perçante et une tranchante), de pièces retouchées et de fragments de lamelles à surface brillante. Les 
roches tenaces sont absentes, et la céramique n'offre que quelques tessons informes à gros dégraissants.

4 La matière première reste d'approvisionnement local avec pour l'essentiel le silex bédoulien du plateau de Sault et le silex oligocène gîtant dans la combe d'Aurel.

5 L'occupation néolithique-chalcolithique du site est notoire avec quelques éléments qui pourraient se rattacher à la culture chasséenne.

\section{Commune de Montbrun-les-Bains}

6 Au sud de la commune s'ouvre un passage naturel, le fossé d'effondrement d'Aurel ou combe d'Aurel, qui permet de rejoindre le plateau de Sault. Cette combe s'organise en plusieurs petits vallons bien abrités dont celui dit du Grand Chavoul.

7 À la fin du XIX ${ }^{\mathrm{e}}$ s., Roger Valentin du Cheylard signale "une station magdalénienne » (Bulletin d'Archéologie et de Statistique de la Drôme. 1888, Tome 22) au Grand Chavoul ; rien à ce jour ne permet de confirmer une telle hypothèse.

8 Les atouts majeurs du site : orientation est-ouest, abrité du vent dominant (mistral), profusion de matières premières siliceuses, source, abris sous roche, ont attiré les hommes du Néolithique en tout état de cause. Les reliquats de leur occupation sont légion : les artéfacts se ramassent dans le labour d'une parcelle récemment défrichée et dans l'éboulis qui mène à un des abris, celui à gauche en rentrant dans le vallon.

9 La part lithique comprend de nombreux fragments de lames et lamelles dont certaines débitées après chauffe, deux nucléus - un à enlèvements laminaires et un autre chauffé à enlèvements lamellaires -, un gros fragment de dormant de meule, deux pointes de flèches (une perçante, une tranchante) une hache en roche tenace polie, un percuteur en pierre verte allochtone.

10 Comme pour le site précédent, la matière première choisie est issue des mêmes gîtes locaux avec l'apport d'une belle lame à trois pans débitée dans le typique silex de la combe de Levant de Leaunier à Veaux (Malaucène - Vaucluse).

11 La céramique participe avec des tessons non roulés, additionnés de gros dégraissants de calcite, de différentes épaisseurs de tranche dont un présente un rebord et deux autres offrent un décor de chevrons gravés avant cuisson.

12 Le fond néolithique semble donc évident avec une occupation pérenne depuis le Chasséen a minima.

\section{Commune de Reilhanette}

13 Sur le site de Roche Vieille, il ne reste que bien peu d'indices de l'occupation humaine préhistorique des deux abris de ce monolithe de Stampien. La terre noirâtre, pulvérulente, difficile d'accès, n'a livré que des tessons informes de céramique à engobe rouge et noire. Les artefacts lithiques, eux aussi, collectés en pied de roche, ne permettent pas de former une appartenance culturelle. 


\section{Commune de Barret-de-Lioure}

14 Sur le site du Moulin, l'installation humaine - Chalcolithique - aux pieds de ce superbe rocher burdigalien, mille fois bouleversée (y compris à coups de bulldozer) livre toujours un nombre considérable de reliquats lithiques et céramiques (A.-C. Pahin, 1984, 1986, 1987, 1988). Il resterait pour autant à enrichir les données par une investigation scientifique de la faille (véritable abri naturel) qui s'ouvre dans la roche et dont la sédimentation laisse entrevoir en coupe des ossements non identifiés.

INDEX

operation Prospection inventaire (PI)

Index géographique : Rhône-Alpes, Drôme (26), Aulan, Montbrun-les-Bains, Reilhanette

Index chronologique : Chalcolithique, Holocène, Néolithique

\section{AUTEURS}

PIERRE ANDRÉ

BEN 